\title{
Correction: The high-density lipoprotein receptor Scarb1 is required for normal bone differentiation in vivo and in vitro
}

Irina L. Tourkova - Steven F. Dobrowolski - Cassandra Secunda • Mone Zaidi • loanna Papadimitriou-Olivgeri • Dionysios J. Papachristou $\cdot$ Harry C. Blair

Published online: 15 January 2020

(c) United States and Canadian Academy of Pathology 2020

\section{Correction to: Laboratory Investigation} https://doi.org/10.1038/s41374-019-0311-0

Author 'Dionysios J. Papachristou' was listed in the original article as 'Dionysios J. Papachristiou'. However, he should be listed as 'Dionysios J. Papachristou'. This has been addressed by means of this correction article. The original article has also been updated. 